\title{
Single-institutional experience of clinicopathological analysis and treatment for lung cancer patients with human immunodeficiency virus infection
}

\author{
SATOSHI TAKAHASHI ${ }^{1,2}$, YUSUKE OKUMA ${ }^{1,3}$, KAGEAKI WATANABE $^{1}$, \\ YUKIO HOSOMI $^{1}$, AKIFUMI IMAMURA ${ }^{4}$, TATSURU OKAMURA ${ }^{1}$ and AKIHIKO GEMMA ${ }^{2}$
}

\begin{abstract}
${ }^{1}$ Department of Thoracic Oncology and Respiratory Medicine, Tokyo Metropolitan Cancer and Infectious Diseases Center Komagome Hospital, Tokyo 113-8677; ${ }^{2}$ Department of Pulmonary Medicine and Oncology, Graduate School of Medicine, Nippon Medical School, Tokyo 113-8602; ${ }^{3}$ Division of Oncology, Research Center for Medical Sciences, Jikei University School of Medicine, Tokyo 105-8461; ${ }^{4}$ Department of Infectious Diseases, Tokyo Metropolitan Cancer and Infectious Diseases Center Komagome Hospital, Tokyo 113-8677, Japan
\end{abstract}

Received August 11,2016; Accepted February 13, 2017

DOI: $10.3892 / \mathrm{mco} .2017 .1214$

\begin{abstract}
The advent of antiretroviral therapy has changed the disease spectrum constitution among patients living with human immunodeficiency virus (HIV), while the incidence of death due to non-AIDS-defining cancers, particularly lung cancer, continues to increase in the USA and Europe. However, the availability of detailed reports of the clinical characteristics of lung cancer among Asian populations is limited. The present study retrospectively analyzed the clinical characteristics, treatment regimens and outcomes of lung cancer patients with HIV who were treated in a single institution between 1988 and 2013. Of the 20 lung cancer patients living with HIV included in this study, $90 \%$ were diagnosed since 1996 in the post-antiretroviral era. The median $\mathrm{CD}^{+}{ }^{+}$cell count was $373.5 / \mu 1$, whereas $65 \%$ of the patients were diagnosed with adenocarcinoma and $30 \%$ with squamous cell carcinoma. Epidermal growth factor receptor mutations were detected in 3 (27\%) of the 11 specimens for which data were available, of which $65 \%$ had advanced-stage
\end{abstract}

Correspondence to: Dr Yusuke Okuma, Department of Thoracic Oncology and Respiratory Medicine, Tokyo Metropolitan Cancer and Infectious Diseases Center Komagome Hospital, 3-18-22 Honkomagome, Bunkyo, Tokyo 113-8677, Japan

E-mail: y-okuma@cick.jp

Abbreviations: ADCs, AIDS-defining cancers; ADR, adrenal; AIDS, acquired immunodeficiency syndrome; CDDP, cisplatin; CI, confidence interval; CPT-11, irinotecan; DTX, docetaxel; EGFR, epidermal growth factor receptor; ECOG-PS, eastern cooperative oncology group performance status; ED-SCLC, extensive-disease small-cell lung cancer; GEM, gemcitabine; HIV, human immunodeficiency virus; NADCs, non-AIDS-defining cancers; PEM, pemetrexed; PI, protease inhibitor; PTX, paclitaxel

Key words: non-small-cell lung cancer, small-cell lung cancer, human immunodeficiency virus infection, antiretroviral therapy, non-AIDS-defining cancer disease. Of the 20 patients, 9 underwent surgery, 6 received radiotherapy and 5 received chemotherapy as a first-line treatment. Treatment was generally well-tolerated. The median survival period was 35.8 months for all stages and 14.0 months for advanced stages. The treatment outcomes in our institution were favorable in comparison with previous studies from the USA and Europe, although these findings may be due to ethnic differences or the efficacy of treatment for HIV and lung cancer.

\section{Introduction}

The use of antiretroviral therapy for patients living with human immunodeficiency virus (HIV) has prolonged survival, primarily as a result of reduced mortality from the opportunistic infections associated with acquired immunodeficiency syndrome (AIDS) or AIDS-defining cancers (ADCs) in the two decades that followed the development of antiretroviral therapies. These therapies strongly inhibit HIV replication and restore immunological status. Therefore, as the HIV infection per se is well controlled by antiretroviral therapies, longer survival may be anticipated. As a result, the number of deaths among HIV carriers from a wide variety of cancers, cardiovascular disease and stroke, has recently been increasing due to aging, similar to the general population. By the end of 2012, there were 14,706 patients with HIV infection and 6,719 patients with AIDS in Japan (1). Between 2001 and $2006,71 \%$ of all deaths were due to cancer, compared with $20 \%$ in the pre-antiretroviral therapy era (2). Non-ADCs (NADCs) have emerged as a crucial problem contributing to the increased mortality among HIV carriers. NADCs include lung cancer, breast cancer and hepatocellular carcinoma, which are not associated with an immunocompromised state, whereas ADCs are defined as malignancies within the 23 AIDS-defining diseases, which include Kaposi's sarcoma, non-Hodgkin lymphoma and cervical cancer (3).

Prior to the advent of antiretroviral therapy for HIV, lung cancer patients living with this infection were rare and their prognosis was quite poor (4). However, recent publications 
reported that NADCs are becoming more common compared with ADCs $(5,6)$ and have similar prognoses $(7)$. Between 2000 and 2007, there were an estimated 1,597 lung cancer patients with HIV infection in the 34 states of the USA, while there were 10-50 such cases in Europe (8-11) and only 2 reports $(12,13)$ from Asian countries.

In addition, significant progress has been made over the last decade in lung cancer treatment strategies for use in the general population. For example, the development of novel antitumor agents and strategies has increased the chemotherapeutic options $(14,15)$, resulting in improved prognosis for lung cancer. Ethnic differences in the prognosis of lung cancer and suitable biomarkers, including epidermal growth factor receptor (EGFR), have also been identified. However, as most data on lung cancer in HIV patients were reported in the pre-antiretroviral therapy era ( 1996), these are not applicable in the present antiretroviral therapy era. In addition, reference to previous investigations conducted in other regions may be inappropriate.

The aim of this study was to elucidate the clinical characteristics and outcomes of Japanese lung cancer patients living with HIV who received treatment in a single institution.

\section{Patients and methods}

Study population and data extraction. This retrospective study comprised a survey of HIV-infected patients, who were definitively diagnosed with HIV and were positive for HIV antibodies, as confirmed by western blot analysis or the presence of HIV RNA, and who had lung cancer diagnosed at the Tokyo Metropolitan Cancer and Infectious Diseases Center Komagome Hospital (Tokyo, Japan) between 1988 and 2015. The study protocol was approved by the Institutional Review Boards of the participating institutions, and the following clinical data were collected: Patient age and gender, date of diagnosis of HIV infection and lung cancer, histological type and subtype of lung cancer, biomarker status, clinical stage of lung cancer, smoking history, Eastern Cooperative Oncology Group performance status (ECOG-PS), history of AIDS, $\mathrm{CD} 4^{+}$T-cell count and HIV viral load at the time of lung cancer diagnosis, and exposure to antiretroviral therapy. Lung cancer treatments and related toxicities were also surveyed.

Statistical analysis. The patient characteristics and clinical outcomes are summarized in Table I. Survival was estimated from the date of lung cancer diagnosis to the date of death from any cause or the date of the last follow-up. Relevant end-points were selected to reflect clinical practice due to the retrospective nature of the data, and the Kaplan-Meier method was used to estimate 1-, 2- and 5-year overall survival. All statistical analyses were performed using JMP software, version 11 (SAS Institute Inc., Cary, NC, USA).

\section{Results}

Characteristics of HIV-infected patients. A total of 20 lung cancer patients living with HIV were identified, which included 18 patients $(90 \%)$ who were diagnosed in the post-antiretroviral era (i.e., since 1996). All the patients were male, with a median age of 61.0 years (range, 39-77 years), and the majority had a history of smoking. The median latency period from HIV diagnosis to lung cancer diagnosis in 8 patients was 4.5 months (range, 0-19.1 months) (Table I). At the time of lung cancer diagnosis, 5 patients $(25 \%)$ were receiving antiretroviral therapy. The median serum $\mathrm{CD}^{+}{ }^{+}$cell count was 373.5 cells $/ \mu 1$ and HIV viral load was detected in $11(55 \%)$ of the 20 patients, which included 2 (10\%) diagnosed with stage A1, 15 (75\%) with stage A2 and $3(15 \%)$ with stage A3 disease, according to the Centers for Disease Control and Prevention Classification (16).

Clinical characteristics of lung cancer. The histological subtype of lung cancer was adenocarcinoma in 13 patients, squamous cell carcinoma in 6 , and small-cell lung cancer in 1 patient. Of the 11 tumor samples available for analysis, 3 (27.3\%) harbored EGFR mutations, whereas none carried the anaplastic lymphoma kinase fusion oncogene. In regard to lung cancer stage, 13 patients (65\%) had advanced disease (stage $\geq \mathrm{III}$ ) and 7 patients had stage I disease (Table II).

Treatment outcomes for lung cancer. Staging and treatment of lung cancer in the majority $(83.7 \%)$ of the patients with HIV infection were performed in accordance with the guidelines of Japan Lung Cancer Society (17). Concurrent chemoradiotherapy was the most common reason among patients deemed unfit for standard care. However, 3 patients recently received chemoradiotherapy concurrent with platinum-doublet chemotherapy (18), without reported severe toxicity or treatment-related deaths.

Of the 20 patients with lung cancer and HIV infection, 9 underwent surgery, 6 received radiotherapy and 5 received chemotherapy as first-line treatment. Treatment was tolerated by all the patients. One patient received cisplatin-based adjuvant chemotherapy, 3 received chemoradiotherapy concurrent with a platinum-based regimen, and 5 had advanced-stage disease (Table III).

The median survival time was 35.8 months for all stages and 14.0 months for stage IV patients. For patients with stage $\geq \mathrm{III}$ disease, the 1- and 2-year survival rates were 46.1 and $19.2 \%$, respectively (Table IV).

\section{Discussion}

This retrospective analysis demonstrated that survival of lung cancer patients with HIV was longer compared with the historical outcomes for lung cancer patients without HIV infection. The first lung cancer patient living with HIV infection was reported in 1984 by Irwin et al (19); prior to the advent of antiretroviral therapy, lung cancer patients living with HIV were rare and relatively younger, and their prognosis was significantly poorer compared with that of lung cancer patients without HIV infection. As a result of the effectiveness of antiretroviral therapy, patient mortality due to opportunistic infections associated with AIDS has decreased significantly; the survival of patients living with HIV is expected to improve, although the spectrum of complicating diseases continues to change. Due to the immunocompromised state, the prevalence of ADCs, such as Kaposi's sarcoma, non-Hodgkin lymphoma and cervical cancer, continues to decrease with the use of antiretroviral therapies that strongly inhibit HIV replication and restore immune function. However, the incidence of NADCs, including anal cancer, lung cancer, hepatocellular carcinoma and Hodgkin's 
Table I. Demographic characteristics of lung cancer patients with HIV infection $(n=20)$.

\begin{tabular}{|c|c|c|}
\hline Characteristics & No. of patients & $(\%)$ \\
\hline $\begin{array}{l}\text { Median age at diagnosis with } \\
\text { lung cancer, years (range) }\end{array}$ & $61.0(39-77)$ & - \\
\hline Male gender & 20 & 100.0 \\
\hline \multicolumn{3}{|l|}{ Tobacco use } \\
\hline Smoker & 19 & 95.0 \\
\hline Never smoker & 1 & 5.0 \\
\hline Pack years, median (range) & $33(29-132)$ & - \\
\hline \multicolumn{3}{|l|}{ ECOG PS } \\
\hline 0,1 & 18 & 90.0 \\
\hline 2 & 2 & 10.0 \\
\hline 3,4 & 0 & 0.0 \\
\hline \multicolumn{3}{|l|}{ HIV risk factor } \\
\hline MSM & 11 & 55.0 \\
\hline Heterosexual/others & 7 & 35.0 \\
\hline Unknown & 2 & 10.0 \\
\hline \multicolumn{3}{|l|}{ Latency } \\
\hline Median latency, years (range) & $4.5(0-19.1)$ & \\
\hline \multirow{2}{*}{\multicolumn{3}{|c|}{$\begin{array}{l}\text { Antiretroviral therapy at lung } \\
\text { cancer onset }\end{array}$}} \\
\hline & & \\
\hline Yes/no & $5 / 15$ & $25.0 / 75.0$ \\
\hline $\begin{array}{l}\text { Median } \mathrm{CD}^{+} \text {cell count at lung } \\
\text { cancer diagnosis, cells/ } \mu \text { l (range) }\end{array}$ & $373.5(52635)$ & - \\
\hline \multicolumn{3}{|l|}{ HIV viral load (copies/ $\mu 1)$} \\
\hline Undetectable & 9 & 45.0 \\
\hline$\geq 50$ & 11 & 55.0 \\
\hline \multicolumn{3}{|l|}{ CDC classification } \\
\hline A1 & 2 & 10.0 \\
\hline A2 & 15 & 75.0 \\
\hline A3 & 3 & 15.0 \\
\hline
\end{tabular}

ECOG, Eastern Clinical Oncology Group;; PS, performance status; HIV, human immunodeficiency virus; MSM, men who have sexual intercourse with men; CDC, Center for Disease Control.

lymphoma, continues to increase. Among NADCs, lung cancer is the most common, accounting for $\sim 5 \%$ of all deaths. At present, the incidence of lung cancer and HIV in the USA is no longer considered a rare occurrence, and there are currently several patients living with HIV in Japan and Europe.

The standardized incidence ratio of lung cancer patients living with HIV demonstrated that the risk of mortality adjusted for age and gender is 1.4-4.5-times higher compared with that for lung cancer patients without HIV infection. The results of a meta-analysis demonstrated that the relative risk was 2.72 (95\% confidence interval: 1.91-3.87) and that the risk of lung cancer was higher for patients with HIV infection compared with those without HIV. An immunocompromised state due to HIV infection is considered as the most critical risk factor for the occurrence of cancer, including lung cancer. Wistuba et al (20) reported that microsatellite alternations
Table II. Demographic characteristics of lung cancer in patients with HIV infection.

\begin{tabular}{lcc}
\hline & $\begin{array}{c}\text { No. of } \\
\text { patients }\end{array}$ & $(\%)$ \\
\hline Histology & & \\
Adenocarcinoma & 13 & 65.0 \\
Squamous cell carcinoma & 6 & 30.0 \\
Small-cell carcinoma & 1 & 5.0 \\
EGFR mutation status & & \\
(data available in 11 cases) & & \\
Mutation & 3 & 27.3 \\
Wildtype & 8 & 72.7 \\
Stage & & \\
I (A/B) & $7(4 / 3)$ & 35.0 \\
II (A/B) & 0 & 0.0 \\
III (A/B) & $8(3 / 5)$ & 40.0 \\
IV & 5 & 25.0 \\
Metastatic sites at diagnosis (overlap) & & \\
Brain/liver/bone/lymph nodes/adrenal & $3 / 1 / 1 / 1 / 2$ & - \\
Treatment modalities & & \\
Surgery & 9 & 45.0 \\
Radiotherapy & 6 & 30.0 \\
Chemotherapy & 5 & 25.0 \\
\hline
\end{tabular}

HIV, human immunodeficiency virus; EGFR, epidermal growth factor receptor.

occurred at a six times higher rate in lung cancer specimens from patients with HIV infection compared with those without $\mathrm{HIV}$, and that these genomic instabilities promote carcinogenesis. However, another clinical investigation demonstrated that increased HIV viral load or decreased $\mathrm{CD}^{+}{ }^{+}$cell count is not associated with carcinogenesis (21).

The median age of lung cancer patients living with HIV is reportedly 45-50 years, whereas for those without HIV it is 62 years, although recent surveillance has reported a median age of 60 years $(22,23)$. In the post-antiretroviral era, lung cancer patients living with HIV are younger and recent surveillance has demonstrated that the age of these patients is similar to that of the non-HIV population (7). Clinical staging of lung cancer patients living with HIV demonstrated that $75-90 \%$ have advanced-stage disease, including $18-29 \%$ with stage III and $50-68 \%$ with stage IV disease. Adenocarcinoma is the most common histological subtype (31-52\%), followed by squamous cell carcinoma (17-39\%), large-cell carcinoma (3-16\%), small-cell carcinoma (1-14\%) and bronchoalveolar carcinoma $(>2 \%)$. Among the patients included in a former study, $74 \%$ had a previous history of AIDS and 55\% received antiretroviral therapy (4). The latency period between diagnosis of HIV and lung cancer appeared to differ by gender, being 4.1 years for women and 7.7 years for men. The reported survival period for lung cancer patients living with HIV is 1-10 months. A recent publication noted that the prognosis of lung cancer patients with HIV infection remained poor in the post-antiretroviral era 
Table III. Treatment with further-line chemotherapy.

Type of cancer Treatment (dose in $\left.\mathrm{mg} / \mathrm{m}^{2}\right) \quad$ Grade $\geq 3$ treatment-related complications

\section{ED-SCLC}

$$
1
$$

Stage III

\section{NSCLC}

2
$3^{\mathrm{a}}$
4
5

Stage IV

NSCLC

$\begin{array}{ll}6 & \text { CDDP } 30 \mathrm{mg} / \mathrm{m}^{2}+\mathrm{CPT}-1160 \mathrm{mg} / \mathrm{m}^{2} \\ 7 & \text { CDDP } 80 \mathrm{mg} / \mathrm{m}^{2}+\text { GEM } 1,000 \mathrm{mg} / \mathrm{m}^{2} \\ 8 & \text { CDDP } 75 \mathrm{mg} / \mathrm{m}^{2}+\text { PEM } 500 \mathrm{mg} / \mathrm{m}^{2} \\ 9 & \text { CDDP } 60 \mathrm{mg} / \mathrm{m}^{2}+\mathrm{S}-180 \mathrm{mg} / \mathrm{m}^{2}\end{array}$

\author{
CDDP $80 \mathrm{mg} / \mathrm{m}^{2}+$ XRT (60 Gy) \\ CDDP $80 \mathrm{mg} / \mathrm{m}^{2}+$ GEM $1,000 \mathrm{mg} / \mathrm{m}^{2}$ \\ CDDP $40 \mathrm{mg} / \mathrm{m}^{2}+$ DTX $40 \mathrm{mg} / \mathrm{m}^{2}+$ XRT (59.4 Gy) \\ CBDCA (AUC 2) + PTX 45 mg/m² + XRT (58 Gy)
}

Neutropenia
Neutropenia

Thrombocytopenia, elevated creatinine Pneumonitis, esophagitis, neutropenia Thrombocytopenia, pneumonitis, esophagitis

${ }^{a}$ Adjuvant setting. Erlotinib $150 \mathrm{mg} /$ day, docetaxel $60 \mathrm{mg} / \mathrm{m}^{2} \mathrm{q} 3 \mathrm{wks}$, amrubicine $35 \mathrm{mg} / \mathrm{m}^{2} \mathrm{q} 3 \mathrm{wks}$. ED-SCLC, extensive-disease smallcell lung cancer; NSCLC, non-smallcell lung cancer; CDDP, cisplatin; CPT-11, irinotecan; GEM, gemcitabine; DTX, docetaxel; PTX, paclitaxel; PEM, pemetrexed; CBDCA, carboplatin; AUC, area under the curve; XRT, external beam radiation therapy.

Table IV. Treatment efficacy in lung cancer patient with advanced-stage disease.

\begin{tabular}{ll}
\hline $\begin{array}{l}\text { Response to chemotherapy } \\
\text { for patients with advancedstage } \\
\text { disease }(\mathrm{n}=5)\end{array}$ & $\begin{array}{c}\text { Median survival } \\
\text { time, months } \\
(95 \% \mathrm{CI})\end{array}$ \\
\hline In all cases & $36.6(17.6-$ not reached) \\
Stage IIIB & $25.1(16.8-$-not reached) \\
Stage IV & $14.8(2.5-46.0)$ \\
$1-$ and 2 year survival rate & 46.1 and $19.2 \%$, \\
in advanced stages (III-IV) & respectively
\end{tabular}

Of the 5 patients, 3 (60\%) responded to chemotherapy. CI, confidence interval.

compared with the non-HIV population, with survival ranging from 5.2 to 8.1 months (7). According to histological subtype, the median survival is 5 months for non-small-cell lung cancer and 7 months for small-cell lung cancer. Important prognostic factors for lung cancer with HIV infection are reportedly PS, adequate organ function and use of antiretroviral therapy. A $\mathrm{CD}^{+}$cell count of $>200 / \mu$ l is useful as an indication for chemotherapy for advanced-stage disease (24).

As several types of antiretroviral therapies and anticancer agents are metabolized via the CYP450 pathway, drug interactions should be taken into consideration. In particular, the use of a protease inhibitor (PI) or non-nucleic acid reverse transcriptase inhibitor may increase toxicity in vitro. Decreased effectiveness of antiretroviral therapy may lead to an immunocompromised state and increased risk of toxicity or decreased efficacy of antitumor agents (4). It has been suggested that raltegravir and maraviroc, which do not interact

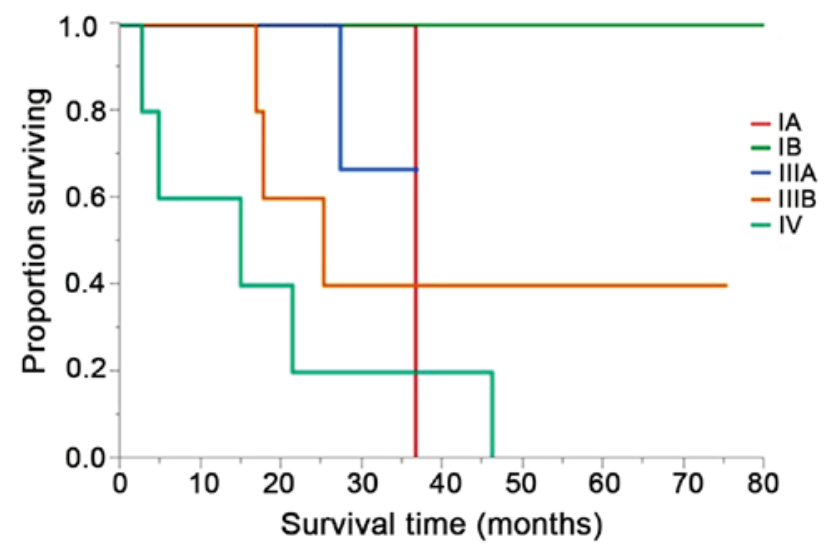

Figure 1. Survival curves of lung cancer patients with human immunodeficiency virus infection according to disease stage.

with other chemotherapeutic agents, should be replaced (4). A trial conducted by the AIDS Malignancy Consortium for HIV patients with solid tumors recommended decreasing the dose of sunitinib among patients receiving PIs due to the increased risk of toxicity (24).

Recent research has suggested that advanced lung cancer patients living with HIV should receive chemotherapy, as is the case for patients without HIV infection (13). However, severe myelosuppression may result from HIV infection per se and the tolerability to chemotherapy at the standard dose remains unknown due to the lack of relevant clinical trials. Importantly, chemotherapy-induced nausea and vomiting should be managed in order to maintain adherence to antiretroviral therapy regimens. In addition, smoking cessation is crucial to ensure the efficacy of therapy, as the proportion of cigarette smokers is higher among patients with HIV infection compared with the general population. Furthermore, it is 
important to test for cardiovascular disease and pulmonary complications associated with smoking, and adequate primary prevention for opportunistic infections should be implemented when the $\mathrm{CD} 4^{+}$cell count is low.

Treatment of patients with advanced lung cancer who are also harboring sensitizing mutations of EGFR to tyrosine kinase inhibitors is not as effective as for those with wild-type EGFR $(25,26)$. EGFR mutations are more common among East Asians, women, non-smokers and adenocarcinoma patients; an estimated $30 \%$ of Asians with lung cancer harbor an EGFR mutation compared with $<10 \%$ of Caucasians. Japanese surveillance found that $28 \%$ of all patients in the HIV cohort had lung cancer, similar to the non-HIV cohort, although the majority were male smokers (13).

The results of the present study were similar to those of previous investigations, although the prognosis was better, as a higher number of patients were diagnosed at an early stage, and those with advanced-staged disease commonly received chemotherapy. The frequency of EGFR mutations affects prognosis, and a similar proportion of mutations was observed between the HIV and non-HIV cohorts, although most occurred in men and heavy smokers. In our experience, the tolerance to surgery, radiotherapy and chemotherapy in these patients is relatively good, even for those receiving concurrent chemoradiotherapy. The results of this study demonstrated that factors associated with better clinical outcomes included good PS, stable HIV infection and standard treatment.

\section{Acknowledgements}

The authors would like to thank Enago (www.enago.jp) for reviewing the English in this manuscript.

\section{References}

1. UNAIDS: 2012 UNAIDS Report on the Global AIDS Epidemic: http://www.unaids.org/en/resources/publications/2012/name, 76121, en.asp, 2012. Accessed April 5, 2017.

2. Crum-Cianflone N, Hullsiek KH, Marconi V, Weintrob A, Ganesan A, Barthel RV, Fraser S, Agan BK and Wegner S: Trends in the incidence of cancers among HIV-infected persons and the impact of antiretroviral therapy: A 20-year cohort study. AIDS 23: 41-50, 2009.

3. Schneider E, Whitmore S, Glynn KM, Dominguez K, Mitsch A and McKenna MT; Centers for Disease Control and Prevention (CDC): Revised surveillance case definitions for HIV infection among adults, adolescents and children aged $<18$ months and for HIV infection and AIDS among children aged 18 months to $<13$ years-United States, 2008. MMWR Recomm Rep 57: 1-12, 2008.

4. Pakkala S and Ramalingam SS: Lung cancer in HIV-positive patients. J Thorac Oncol 5: 1864-1871, 2010.

5. Engels EA, Pfeiffer RM, Goedert JJ, Virgo P, McNeel TS, Scoppa SM and Biggar RJ; HIV/AIDS Cancer Match Study: Trends in cancer risk among people with AIDS in the United States 1980-2002. AIDS 20: 1645-1654, 2006.

6. Robbins HA, Pfeiffer RM, Shiels MS, Li J, Hall HI and Engels EA: Excess cancers among HIV-infected people in the United States. J Natl Cancer Inst 107: dju503, 2015.

7. Rengan R, Mitra N, Liao K, Armstrong K and Vachani A: Effect of HIV on survival in patients with non-small-cell lung cancer in the era of highly active antiretroviral therapy: A population-based study. Lancet Oncol 13: 1203-1209, 2012.

8. Engsig FN, Kronborg G, Larsen CS, Pedersen G, Pedersen C, Gerstoft $\mathrm{J}$ and Obel N: Lung cancer in HIV patients and their parents: A Danish cohort study. BMC Cancer 11: 272, 2011.

9. Clifford GM, Lise M, Franceschi S, Egger M, Bouchardy C, Korol D, Levi F, Ess S, Jundt G, Wandeler G, et al: Lung cancer in the Swiss HIV cohort study: Role of smoking, immunodeficiency and pulmonary infection. Br J Cancer 106: 447-452, 2012.
10. Lanoy E, Spano JP, Bonnet F, Guiguet M, Boué F, Cadranel J, Carcelain G, Couderc LJ, Frange P, Girard PM, et al: The spectrum of malignancies in HIV-infected patients in 2006 in France: The ONCOVIH study. Int J Cancer 129: 467-475, 2011.

11. Dal Maso L, Polesel J, Serraino D, Lise M, Piselli P, Falcini F, Russo A, Intrieri T, Vercelli M, Zambon P, et al: Pattern of cancer risk in persons with AIDS in Italy in the HAART era. $\mathrm{Br}$ J Cancer 100: 840-847, 2009.

12. Petoumenos K, Hui E, Kumarasamy N, Kerr SJ, Choi JY, Chen YM, Merati T, Zhang F, Lim PL, Sungkanuparph S, et al: Cancers in the TREAT Asia HIV observational database (TAHOD): A retrospective analysis of risk factors. J Int AIDS Soc 13: 51, 2010.

13. Okuma Y, Tanuma J, Kamiryo H, Kojima Y, Yotsumoto M, Ajisawa A, Uehira T, Nagai H, Takeda Y, Setoguchi Y and Okada S: A multi-institutional study of clinicopathological features and molecular epidemiology of epidermal growth factor receptor mutations in lung cancer patients living with human immunodeficiency virus infection. J Cancer Res Clin Oncol 141: $1669-1678,2015$

14. Ciuleanu T, Brodowicz T, Zielinski C, Kim JH, Krzakowski M, LaackE, Wu YL, Bover I, Begbie S, Tzekova V, et al: Maintenance pemetrexed plus best supportive care versus placebo plus best supportive care for non-small-cell lung cancer: A randomised, double-blind, phase 3 study. Lancet 374: 1432-1440, 2009.

15. Sandler A, Gray R, Perry MC, Brahmer J, Schiller JH, Dowlati A, Lilenbaum R and Johnson DH: Paclitaxel-carboplatin alone or with bevacizumab for non-small-cell lung cancer. N Engl J Med 355: 2542-2550, 2006.

16. HIV Classification: CDC and WHO Staging Systems: https://www.aidsetc.org/guide/hiv-classification-cdc-and-whostaging-systems. Accessed November 23, 2016.

17. The Japan lung cancer society: guideline for diagnosis and treatment of lung cancer 2015: https://www.haigan.gr.jp/modules/ guideline/index.php?content_id=3. Accessed November 23, 2016.

18. Okuma Y, Yanagisawa N, Hosomi Y, Imamura A, Okamura T, Kato K and Negishi K: Concomitant chemoradiotherapy and antiretroviral therapy for HIV-infected patients with locoregionally advanced non-small cell lung cancer: Benefit and tolerability of treatment in 2 cases. Onkologie 36: 586-590, 2013.

19. Irwin LE, Begandy MK and Moore TM: Adenosquamous carcinoma of the lung and the acquired immunodeficiency syndrome. Ann Intern Med 100: 158, 1984.

20. Wistuba II, Behrens C, Milchgrub S, Virmani AK, Jagirdar J, Thomas B, Ioachim HL, Litzky LA, Brambilla EM, Minna JD and Gazdar AF: Comparison of molecular changes in lung cancers in HIV-positive and HIV-indeterminate subjects. JAMA 279: 1554-1559, 1998

21. Lavolé A, Chouaïd C, Baudrin L, Wislez M, Raguin G, Pialoux G, Girard PM, Milleron B and Cadranel J: Effect of highly active antiretroviral therapy on survival of HIV infected patients with non-small-cell lung cancer. Lung Cancer 65: 345-350, 2009.

22. White CS, Haramati LB, Elder KH, Karp J and Belani CP: Carcinoma of the lung in HIV-positive patients: Findings on chest radiographs and CT scans. AJR Am J Roentgenol 164: 593-597, 1995.

23. Grubb JR, Moorman AC, Baker RK and Masur H: The changing spectrum of pulmonary disease in patients with HIV infection on antiretroviral therapy. AIDS 20: 1095-1107, 2006.

24. Rudek MA, Moore PC, Mitsuyasu RT, Dezube BJ, Aboulafia D, Gerecitano J, Sullivan R, Cianfrocca ME, Henry DH, Ratner L, et al: A phase 1/pharmacokinetic study of sunitinib in combination with highly active antiretroviral therapy in human immunodeficiency virus-positive patients with cancer: AIDS Malignancy Consortium trial AMC 061. Cancer 120: 1194-1202, 2014

25. Inoue A, Sugawara S, Yamazaki K, Maemondo M, Suzuki T, Gomi K, Takanashi S, Inoue C, Inage M, Yokouchi H, et al: Randomized phase II trial comparing amrubicin with topotecan in patients with previously treated small-cell lung cancer: North Japan lung cancer study group trial 0402. J Clin Oncol 26: 5401-5406, 2008.

26. Mitsudomi T, Morita S, Yatabe Y, Negoro S, Okamoto I, Tsurutani J, Seto T, Satouchi M, Tada H, Hirashima T, et al: Gefitinib versus cisplatin plus docetaxel in patients with non-small-cell lung cancer harbouring mutations of the epidermal growth factor receptor (WJTOG3405): An open label, randomised phase 3 trial. Lancet Oncol 11: 121-128, 2010. 